Egyptian Journal of Aquatic Biology \& Fisheries

Zoology Department, Faculty of Science,

Ain Shams University, Cairo, Egypt.

ISSN $1110-6131$

Vol. 25(1): 909 - 918 (2021)

www.ejabf.journals.ekb.eg

\title{
Modulatory effect of pomegranate peel against cold and salinity stress in the monosex Nile tilapia, Oreochromis niloticus
}

\author{
Ahmed E. A. Badrey ${ }^{1}$, Mahmoud M. S. Farrag ${ }^{1}$, Mohamed M. M. Toutou ${ }^{2}$, \\ Mohsen A. Moustafa ${ }^{1}$ and Alaa G. M. Osman ${ }^{1}$ \\ 1- Department of Zoology, Faculty of Science, Al-Azhar University (Assiut branch), Egypt. \\ 2- National Institute of Oceanography \& Fisheries, Alexandria, Egypt.
}

"Corresponding Author: gmal_ahmed77@yahoo.com

\section{ARTICLE INFO}

Article History:

Received: April 9, 2020

Accepted: Jan. 28, 2021

Online: Feb. 28, 2021

Keywords:

Oreochromis niloticus, pomegranate peel, temperature,

Salinity.

\section{ABSTRACT}

A total of 360 monosex Nile tilapia (O. niloticus) fingerlings (mean individual initial weight $=30.8 \pm 2.0 \mathrm{~g}$ ) were divided into eight equal treatments, including a control. Each treatment, including the control, consisted of three equal replicates (15 fish per replicate). The fish in the control group were fed a basal diet containing $25 \%$ protein. In the other 7 treatments, the basal diet was supplemented with pomegranate peel at a rate of $1,2,3,5,10,15$ or $20 \%$. For 90 days, diets were fed 3 times daily at a rate of 7 to $5 \%$ of fish body weight. Afterwords, 3 fish from each replicate of the control and treatment groups were exposed to a temperature of $4^{\circ} \mathrm{C}$. The first mortality was recorded at 47.3 seconds in the control group. While Nile tilapia fed with pomegranate peel exhibited a delay in the time of mortality compared to the control. Also, 3 fish from each replicate of the control and treatment groups were exposed to different salinities of 15, 25, and $37 \%$ for 6 days. A $100 \%$ mortality was recorded in the fish exposed to 25 and $37 \%$ salinity, while those exposed to $15 \%$ salinity exhibited $0 \%$ mortality. The present results showed that feeding pomegranate-enriched diets could improve the stressors resistance and delay mortality of the monosex Nile tilapia.

\section{INTRODUCTION}

Fish have a body temperature that is essentially the same as that of the surrounding water (FRY, 1967; Badrey, 2019) therefore, their entire physiology, including immune function, is influenced by the environmental temperature. Knowledge about the effects of environmental temperature on fish species is critical for the identification of the optimal management strategies for both wild and aquaculture species (Wang et al., 2017). All organisms have a thermal death point, and any increase and/or decrease in the temperature in habitats would have a significant effect on their general metabolism (Dadras et al. , 2017). Moreover, the immune function of fish species could be negatively 
impacted by stress responses to temperatures above their physiological range (Dominguez et al., 2004).

Given the limited space available for freshwater aquaculture and pressures in regard to meeting the food demands of the human population, tilapia are currently cultured in brackish water ponds and even in marine cages. One of the constraints in the culture of tilapia in high-salinity environments is their sensitivity to handling and susceptibility to secondary infection (Chang \& Plumb, 1996). Hence, tilapia reared at high salinities experience higher disease outbreaks and mortality than those reared in freshwater. Consequently, intensive research on improving the salinity tolerance of tilapia through modifications of culture techniques or stock improvement has been conducted (Jaspe et al., 2011). The Nile tilapia (Oreochromis niloticus) can only tolerate brackish water with a salinity up to $25 \%$, while the Mozambique tilapia can tolerate salinity up to $40 \%$ o. Red tilapia can survive in pure seawater with salinity up to $32 \%$ (Jaspe \& Caipang, 2011). Hence, tilapia species are the best option for aquaculture in saline environments because they are omnivorous, can be easily reared with artificial feed, survive at low oxygen levels, tolerate a wide range of salinities and can be cultured in a low volume of water at high densities (Iqbal et al., 2012; Ronald $\boldsymbol{e t}$ al., 2014). The pomegranate peel (PP) is an attractive candidate nutritional supplement for animal feed (Badawi \& Gomaa, 2016), containing bioactive compounds and has extensively been studied for its strong antimicrobial and anti-inflammatory effects (Jurenka, 2008). Therefore, the present study was conducted to examine the effects of dietary supplementation with the natural additive pomegranate peel on cold and salinity stress in monosex Nile tilapia.

\section{MATERIALS AND METHODS}

\section{Pomegranate peel}

The pomegranate peel was prepared in the lab before the performance of the experiment. Pomegranate fruits were obtained from the local market at Assiut Governorate in Egypt. The fruits were washed with distilled water and then peeled, and their edible portions were carefully separated. The peels were air dried in a hot air oven at $40^{\circ} \mathrm{C}$ until the moisture content reached approximately $8 \%$ (dry basis). The dry materials were finely ground by using a Lab-Mill, sieved, and then, manually mixed in a plastic container for approximately 15 minutes to ensure homogeneity. A basal control diet consisting $25 \%$ crude protein $(\mathrm{CP})$ and $448.3 \mathrm{kcal} / 100 \mathrm{~g}$ was formulated to fulfil the nutrient requirements of the fish. 


\section{Diets}

The basal control diet was prepared with $10 \%$ yellow corn and $30 \%$ rice bran. The other seven experimental diets were formulated to represent seven dietary treatments, and consisted of the experimental fish diet at rates of 1, 2, 3, 5, 10, 15, and 20\% (Table 1). Fewdrops of oil and additives were then added to the mixture until a homogenous mixture was obtained. Additionally, warm water was gradually added until the diet began to clump, producing a paste with a dough-like consistency. The diet was formed into small balls, and then passed through a commercial meat grinder to create a spaghetti-like extruded diet. The diet was spread on a metal plate and dried in a hot-air oven at $60^{\circ} \mathrm{C}$ for 36 hours. The dried diet was chopped into pellets and sieved through standard sieves to separate the pellets and obtain an appropriate size suitable for the experimental fish size of $1 \mathrm{~mm}$ diameter. The diets were stored in labelled plastic bags in a freezer at $-20^{\circ} \mathrm{C}$ until use.

\section{Fish and experimental design}

A total of 360 monosex Nile tilapia (O. niloticus) fingerlings (mean individual initial weight $=30.8 \pm 2.0 \mathrm{~g}$ ) were divided into eight equal treatments, including a control. Each treatment, including the control, consisted of three equal replicates (15 fish per replicate):

1 - The first group was considered as the control and fed the basal control diet containing $25 \% \mathrm{CP}$ and $448.3 \mathrm{kcal} / 100 \mathrm{~g}$.

2 - The second, third, fourth, fifth, and sixth groups were fed the basal diet with $1 \%$, $2 \%, 3 \%, 5 \%$ and $10 \%$ of the yellow corn replaced with pomegranate peel, respectively.

3 - The seventh and eighth groups were fed diets formulated by replacing all of the yellow corn (10\% of the original diet) and 5\% and $10 \%$ of the rice bran with $15 \%$ and $20 \%$ pomegranate peel, respectively.

For a period of 90 days, fish were fed with these diets 3 times daily at a rate of 7 to $5 \%$ of their body weight. At the end of the feeding period, the fish were examined for their tolerance of cold temperatures and high salinity. For Cold stress, 3 fish from each replicate of the control and treatment groups were exposed to cold temperature $\left(4^{\circ} \mathrm{C}\right)$. Death was defined as the point at which the fish lost balance and did not respond to external stimuli. While for salinity stress, 3 fish from each replicate of the control and treatment groups were exposed to different salinities of 15, 25, and 37\%o for 6 days. 


\section{Statistical analyses}

Data are presented as the mean $\pm \mathrm{SD}$. The results were subjected to one-way analysis of variance (ANOVA) to test the effects of the treatments on fish performance. Data were analyzed using the SPSS program, version 16. Differences between means were compared using Duncan's multiple range test at the $\mathrm{P}<0.05$ level.

Table 1: Composition (\% dry matter) of the experimental diets.

\begin{tabular}{lcccccccc}
\hline \multicolumn{1}{c}{ Ingredients } & \multicolumn{8}{c}{ Composition (\%) of the experimental diets } \\
\cline { 2 - 10 } \multicolumn{1}{c}{ composition (g) } & Control & $\% 1$ & $\% 2$ & $\% 3$ & $\% 5$ & $\% 10$ & $\% 15$ & $\% 20$ \\
\hline Fish meal (65\%) & 70 & 70 & 70 & 70 & 70 & 70 & 70 & 70 \\
Soy bean meal & 250 & 250 & 250 & 250 & 250 & 250 & 250 & 250 \\
Corn gluten & 80 & 80 & 80 & 80 & 80 & 80 & 80 & 80 \\
Yellow corn & 100 & 90 & 80 & 70 & 50 & 0 & 0 & 0 \\
Pomegranate peel & 0 & 10 & 20 & 30 & 50 & 100 & 150 & 200 \\
Wheat bran & 150 & 150 & 150 & 150 & 150 & 150 & 150 & 150 \\
Rice bran & 300 & 300 & 300 & 300 & 300 & 300 & 250 & 200 \\
Fish oil & 20 & 20 & 20 & 20 & 20 & 20 & 20 & 20 \\
Premix & 30 & 30 & 30 & 30 & 30 & 30 & 30 & 30 \\
\multicolumn{1}{c}{$\quad$ Total } & 1000 & 1000 & 1000 & 1000 & 1000 & 1000 & 1000 & 1000 \\
\hline \multicolumn{1}{r}{$\quad$} & & & & & & & &
\end{tabular}

\section{RESULTS}

\section{Effects of low temperature}

At the end of the experimental period, three fishes from each group were randomly exposed to lower temperature $\left(4^{\circ} \mathrm{C}\right)$. The observations showed that all fishes exhibited remarkable changes in behaviour, including a decline in activity and an abrupt loss of equilibrium. The first mortality was recorded at 47.3 seconds in the control group, while the mortalities in the treatment groups were recorded a short time later (Table 2, Fig. 1). The time of mortality in the monosex Nile tilapia fed the diets with the different concentrations of pomegranate peel ranged from 76.3 seconds in the group provided with $3 \%$ pomegranate peel to 94 seconds in the group given 5\% pomegranate peel. In general, mortality was delayed in all the groups fed the different concentrations of pomegranate peel in comparison to the control group (Table 2, Fig. 1).

Table 2: Average \pm SD time of mortality (seconds) in monosex Nile tilapia (O. niloticus) fed diets with different concentrations of pomegranate peel and exposed to a low temperature $\left(4^{\circ} \mathrm{C}\right)$.

\begin{tabular}{ccccccccc}
\hline \multirow{2}{*}{ Treatment } & \multicolumn{7}{c}{ Experimental diet } \\
\cline { 2 - 8 } & Control & $1 \%$ & $2 \%$ & $3 \%$ & $\% 5$ & $10 \%$ & $15 \%$ & $\% 20$ \\
\hline $\begin{array}{c}\text { Average } \pm \\
\text { SD }\end{array}$ & $47.3 \pm 6.7^{\mathrm{c}}$ & $56.0 \pm 8.1^{\mathrm{bc}}$ & $77.6 \pm 4.5^{\mathrm{ab}}$ & $76.3 \pm 3.6^{\mathrm{abc}}$ & $94.0 \pm 24.5^{\mathrm{a}}$ & $84.0 \pm 17.5^{\mathrm{ab}}$ & $85.6 \pm 18.3^{\mathrm{ab}}$ & $85.0 \pm 15.7^{\mathrm{ab}}$
\end{tabular}

Significant differences in means $(\mathrm{P}<0.05)$ are indicated by different superscripts. 


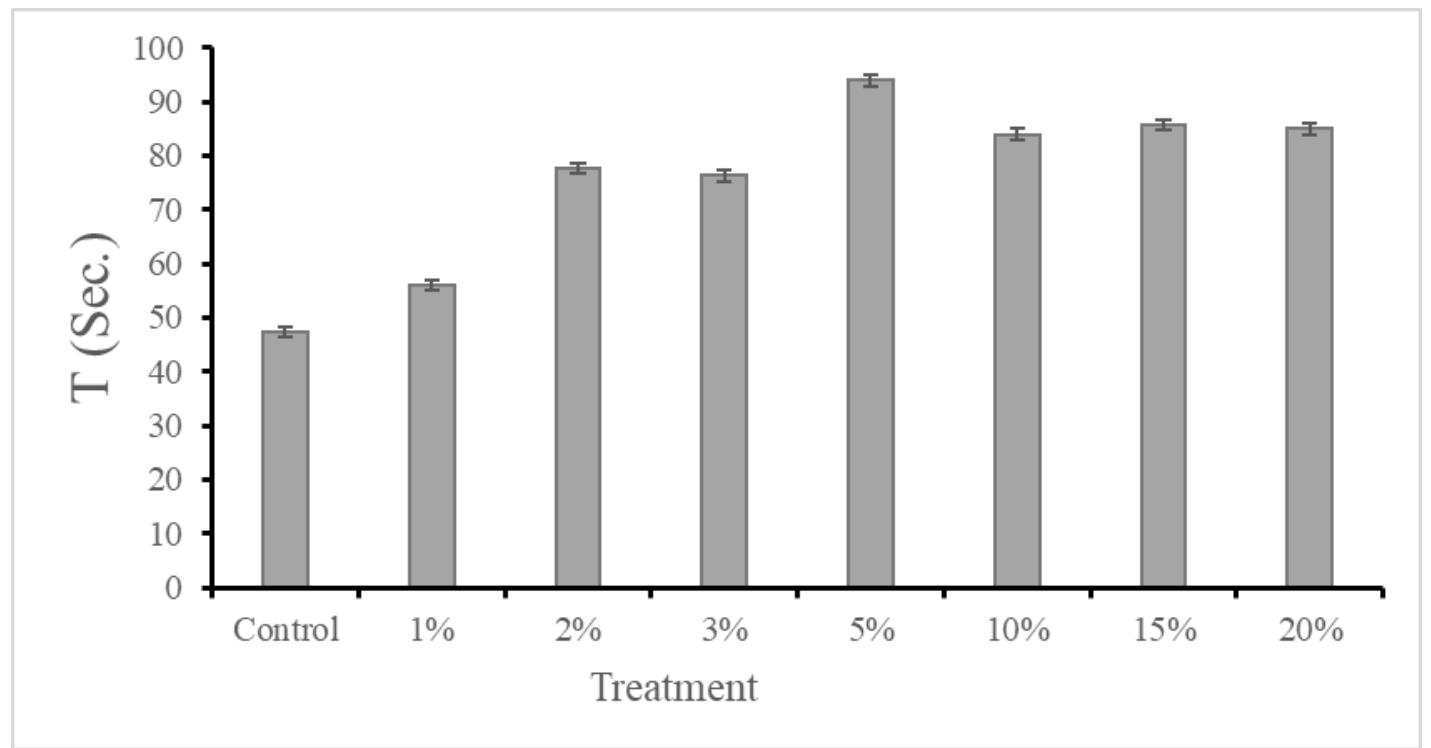

Fig. 1: Average \pm SD time of mortality (seconds) in monosex Nile tilapia (O. niloticus) fed diets with different concentrations of pomegranate peel and exposed to a low temperature $\left(4^{\circ} \mathrm{C}\right)$.

\section{Effects of salinity}

The monosex Nile tilapia exhibited a normal response with no mortality in the control group and the groups fed with different concentrations of pomegranate peel when exposed to $15 \%$ salinity. However, the fish exposed to 25 and $37 \%$ salinity exhibited restlessness, hyperactivity, and erratic behaviour. Additionally, some fish exhibited quick and somewhat continuous movement from the surface to the bottom, especially during the first 2 hours of exposure, after which the fish became very weak, settled at the bottom, and eventually died. Such behaviours increased with an increase in the salinity concentration. The fish exposed to $15 \%$ salinity stayed alive longer than those exposed to 25\% salinity (Table 3, Fig. 2). Mortalities were recorded starting at 11.7 hours among the control fish exposed to $25 \%$ salinity, while mortality was delayed in the fish given diets with different concentrations of pomegranate peel. The fish fed with $2 \%, 3 \%$ and $5 \%$ pomegranate peel showed the best resistance, dying 17.8, 17.4 and 13.1 hours after exposure, respectively (Table 3, Fig. 2). The fish exposed to 37\%o salinity showed faster mortality rates, with higher resistance in the treatment groups than in the control (Table 3, Fig. 2). The mortality rate was significantly delayed in the treatment groups in comparison to the control. The fish fed the different concentrations of pomegranate peel exhibited the same mortality rate (Table 3 ). 
Table 3: Average \pm SD time of resistance before death of monosex Nile tilapia $(O$. niloticus) fed diets with different concentrations of pomegranate peel and exposed to different salinities: 15,25 and $37 \%$.

\begin{tabular}{|c|c|c|c|c|c|c|c|c|}
\hline \multirow{2}{*}{$\begin{array}{l}\text { Treatment } \\
\text { Salinity }\end{array}$} & \multicolumn{8}{|c|}{ Experimental diet } \\
\hline & Control & $1 \%$ & $2 \%$ & $3 \%$ & $\% 5$ & $10 \%$ & $15 \%$ & $\% 20$ \\
\hline $15 \%$ & ...... & & & & & & & \\
\hline & & ..... & ....... & ....... & ....... & ........ & ...... & ......... \\
\hline $25 \%$ & $11.7 \pm 0.6^{\mathrm{d}}$ & $12.5 \pm 0.3^{\mathrm{abc}}$ & $17.8 \pm 0.4^{\mathrm{a}}$ & $17.4 \pm 0.4^{\mathrm{a}}$ & $13.1 \pm 0.8^{b}$ & $13.0 \pm 0.3^{\mathrm{bc}}$ & $12.4 \pm 0.4^{b c d}$ & $\begin{array}{c}12.0 \pm 0.4 \\
\mathrm{~cd}\end{array}$ \\
\hline $37 \%$ & $2.4 \pm 0.0^{\mathrm{b}}$ & $3.3 \pm 0.2^{\mathrm{a}}$ & $3.3 \pm 0.0^{\mathrm{a}}$ & $2.9 \pm 0.5^{\mathrm{ab}}$ & $3.2 \pm 0.0^{\mathrm{a}}$ & $3.4 \pm 0.3^{\mathrm{a}}$ & $3.1 \pm 0.01^{\mathrm{a}}$ & $3.3 \pm 0.3^{\mathrm{a}}$ \\
\hline
\end{tabular}

Significant differences among means within rows $(\mathrm{P}<0.05)$ are indicated by different superscripts.
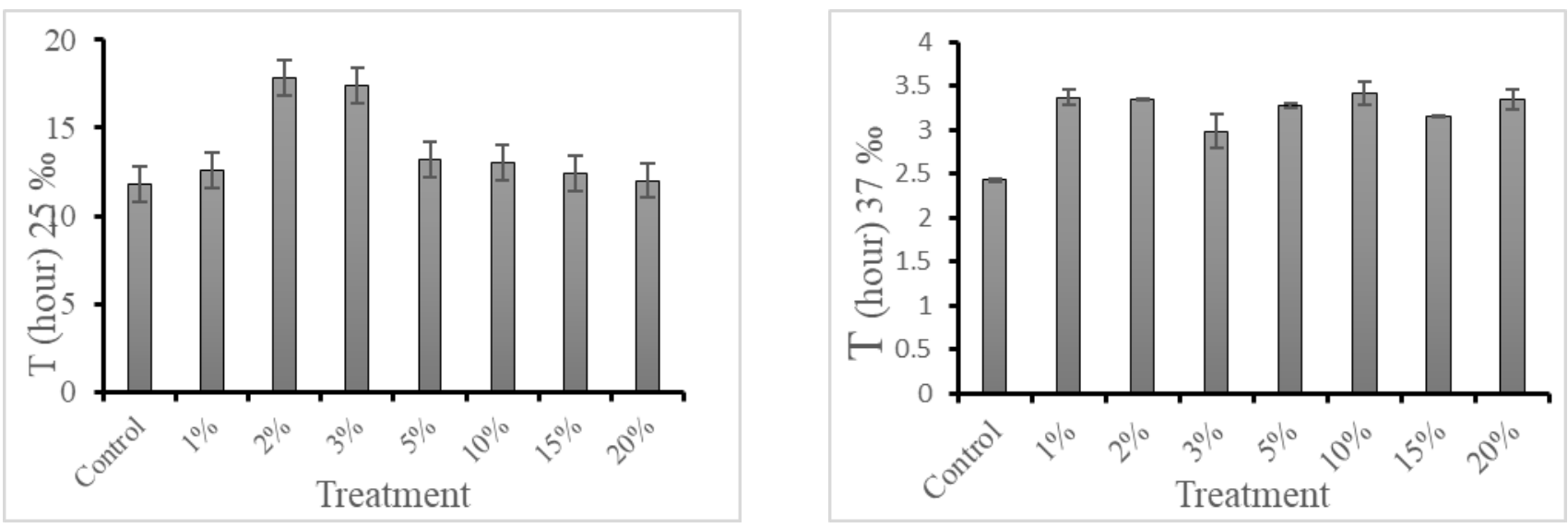

Fig. 2: Average \pm SD time of resistance before death of monosex Nile tilapia (O. niloticus) fed diets with different concentrations of pomegranate peel and exposed to different salinities: $25 \%$ and $37 \%$.

\section{DISCUSSION}

Tilapia are very sensitive to low water temperatures as it stops feeding when the water temperature reaches $16^{\circ} \mathrm{C}$, at which the rates of digestion and absorption are affected (Fayed et al. ,2012).

Mortality in the Nile tilapia has been reported to occur from $13^{\circ} \mathrm{C}$ to $10^{\circ} \mathrm{C}$ (Lahav \& Ra'anan, 1998) and from $11^{\circ} \mathrm{C}$ to $9^{\circ} \mathrm{C}$ (Smitherman et al., 1988). However, Sifa et al. (2002) reported better cold tolerance, with first mortality observed at $11^{\circ} \mathrm{C}$ and total mortality at $7.4^{\circ} \mathrm{C}$. Several studies have shown that the degree of tolerance to lethal temperatures is dependent upon environmental effects, the history of the fish and genetic effects (Cnaani et al., 2000) as well as fish health and nutritional status.

In the present experiment, the monosex Nile tilapia fed the pomegranate peel exhibited a delay in the time of mortality, compared to the control, after exposure to a lowered 
temperature $\left(4^{\circ} \mathrm{C}\right)$. The fish fed no pomegranate peel died quickly after 47.3 seconds. In contrast, the fish fed the diets containing the different concentrations of pomegranate peel exhibited delayed mortality, with higher cold tolerance being recorded in comparison to the control. It has been shown that the concentration of pomegranate peel affects the lipid content of the muscles and liver in Nile tilapia. The higher cold tolerance recorded here could be explained by the presence of antioxidants in the pomegranate peel, which improve the immunity status of the fish. The highest cold tolerance was recorded in the fish fed the diet with the $5 \%$ concentration of pomegranate peel.

Tilapia, despite being freshwater fishes, are believed to have evolved from marine ancestors (Kirk, 1972) therefore, most of these fishes are able to tolerate a wide range of salinities. Adult fish are more salt tolerant than fry and juveniles. Fry and juveniles were found to tolerate direct transfer to water with $19 \%$ salinity without apparent stress or mortality, but $100 \%$ mortality occurred at $27 \%$ (Ntabo, 2012). This result is supported by those in the present work, in which monosex Nile tilapia were found to tolerate up to $15 \%$ salinity with no mortality across all the experimental groups, while $100 \%$ mortality was recorded in the monosex Nile tilapia exposed to salinity levels of $25 \%$ and $37 \%$. According to the present results, monosex Nile tilapia have the ability to survive at 15\% salinity. This result is in accordance with that found by Hassan et al. (2013), who stated that the fish are perfectly able to regulate their body physiology with no mortality at 5\%o salinity, unlike $20 \%$ and $35 \%$ salinity, at which all fishes died. Moreover, the latter author also indicated that the excessive mucus secreted by the fish might help to maintain the homeostasis of the internal fluids as a way to tolerate high salinities.

The control monosex Nile tilapia exposed to $25 \%$ and $37 \%$ salinities died first, after 11.7 and 2.4 hours of exposure, respectively. In contrast, the fish fed the different diets containing pomegranate peel exhibited delayed times of mortality that ranged from 12 to 17.8 hours and 2.9 to 3.4 hours at $25 \%$ and $37 \%$ salinity, respectively. The greatest resistance to salinity was recorded in the group of fish fed the diets containing $2 \%, 3 \%$ and $5 \%$ pomegranate peel after exposure to $25 \%$ salinity. Among the fishes exposed to $37 \%$ salinity, non-significant differences were recorded in the mortality rate among the groups fed the different concentrations of pomegranate peel.

The present results coincided with those of ${ }^{[18]}$ who found $100 \%$ mortality at both 20 and 35\% salinity (Mallat, 1985; Ried $\boldsymbol{e t}$ al., 2006). The observed mortality could be a consequence of the progressive deterioration in the osmotic and ionic regulatory mechanisms, including the ability of the fish to mitigate excessive water loss, leading to osmoregulatory exhaustion, collapse and eventual death (Deacon \& Hecht, 1999). The survival of the fish depends on the ability of the body fluids to function at least for short time in an abnormal range of internal osmotic and ionic concentrations (Kurata, 1959). The migration of fish from freshwater to seawater would normally lead to an increase in the osmotic concentration of the fish blood serum and a change in the ionic contents 
(Gordon, 1959; Miles \& Smith, 1968). The fish exposed to 15\%o salinity showed normal behaviour, while those exposed to $25 \%$ and $37 \%$ salinity exhibited restlessness, hyperactivity, and erratic behaviour during the first 2 hours of exposure, followed by a settlement at the bottom and eventually died. This observation indicated that the fish were approaching their tolerance limits and losing water at a fast rate (Lawson \& Anetekhai, 2011). This behaviour also may be due to biochemical body derangement, including compromised hepatic function (Fadina et al., 1991). The present results showed that feeding pomegranate-enriched diets may be important to improve the stressors resistance and delay mortality of monosex Nile tilapia.

\section{REFERENCES}

Badawi, M. E. and Gomaa, A. M. (2016). Influence of diets supplemented with pomegranate peel extract on performance in Oreochromus niloticus. JPN. J. VET. RES., 64 (Supplement 2): 87-94.

Badrey, A.E.A. (2019). Use of Pomegranate peel (Punica granatum) as growth promoter and immune modulent in monosex Nile tilapia Oreochromis niloticus. Ph.D. Thesis, ALAzhar University, Assiut Branch.

Chang, P. H. and Plumb, J. A. (1996). Effects of salinity on Streptococcus infection of Nile tilapia, Oreochromis niloticus. J Appl Aquacult., 6(1): 39-45.

Cnaani, J.; Robinson, G.E. and Hefetz, A. (2000). The critical period for caste determination in Bombus terrestris and its juvenile hormone correlates. J. Comp. Physiol. A. 186(11):1089-1094.

Dadras, H.; Dzyuba, B.; Cosson, J.; Golpour, A.; Siddique, M.A.M. and Linhart, O. (2017). Effect of water temperature on the physiology of fish spermatozoon function: a brief review. Aquac. Res. 48(3): 729-740.

Deacon, N. and Hecht, T. (1999). The effect of reduced salinity on growth, food conversion and protein efficiency ratio in juvenile spotted grunter, Pomadasys commersonnii (Lacepede) (Teleostei: Haemulidae). Aquac. Res. 30(1): 13-20.

Dominguez, M.; Takemura, A.; Tsuchiya, M. and Nakamura, S. (2004). Impact of different environmental factors on circulating immunoglogulin levels in the Nile tilapia, Oreochromis niloticus. Aquacult., 241(1-4): 491-500.

Fadina, O.O.; Taiwo, V.O. and Ogunsanmi, A.O. (1991). The effects of single and repetitive oral administrative of common pesticide and alcohol on rabbits. Tropical Veterinary. 17: 97-106.

Fayed, A.M.; Azoz, A.A.; Zedan, A.H. and Basyony, M. (2012). Effects of pomegranate peel as antioxidant supplementation on digestibility, blood biochemical and rabbit semen quality. E.J.N.F., 15: 343-354. 
FRY, F.E.J. (1967). Responses of vertebrate poikilotherms to temperature. In Thermobiology (ed. A. H. Rose), London, New York: Academic Press., 375-409.

Gordon, M.S. (1959). Ionic regulation in the Brown trout (Salmon trutta). J. Exp. Biol. 36(2): 227-252.

Hassan, M.; Zakariah, M.I.; Wahab, W.; Muhammad, S.D. and Idris, N. (2013). Histopathological and Behavioral Changes in Oreochromis sp. after Exposure to Different Salinities. J. Fish. Lives., 1:103.

Iqbal, K.J.; Qureshi, I.A.; Ashraf, M.; Rehman, M.H.U.; Khan, N.; Javid, A.; Abbas, F.; Mushtaq, M.M.H.; Rasool, F. and Majeed, H. (2012). Effect of different salinity levels on growth and survival of Nile tilapia (Oreochromis niloticus). J ANIM PLANT SCI., 22(4): 919-922.

Jaspe, C. J. and Caipang, C. M. (2011). Increasing salinity tolerance in tilapias: selective breeding using locally available strains. AACL Bioflux. 4(4): 437-441.

Jaspe, C.J.; Caipang, C.M. and Elle, B.J.G. (2011). Polyculture of white shrimp, Litopenaeus vannamei and milkfish, Chanos chanos as a strategy for efficient utilization of natural food production in ponds. Anim Biol Anim Husb., 3(2): 96-104.

Jurenka, M.T. (2008). Therapeutic applications of pomegranate. A Review. Altern. Med. Rev., 13(2): 128.

Kirk, R.G. (1972). A review of recent developments in Tilapia culture, with special reference to fish farming in the heated effluents of power stations. Aquacult., 1: 45-60.

Kurata, H. (1959). Preliminary report on the rearing of herring larvae. Bull. Fac. Fish., Hokkaido., 20(11): 7-138.

Lahav, E. and Ra'anan, Z. (1998). Cold tolerance of genetically produced all-male tilapia hybrids (Oreochromis aureus). In Tilapia Aquaculture. Proceedings from the Fourth International Symposium on Tilapia. Aquacult., 662-670.

Lawson, E. O. and Anetekhai, M. A. (2011). Salinity tolerance and preference of hatchery reared Nile Tilapia,Oreochromis niloticus (Linnaeus1758). Asian J. Agric. Food. Sci. 3(2):104-110.

Mallat, J. (1985). Fish gill structural changes induced by toxicants and other irritants: a statistical review. Can. J. Fish. Aquat. Sci. 42(4): 630-648.

Miles, H. M. and Smith, L. S. (1968). Ionic regulation in migrating juvenile Coho Salmon, Oncorhynchus kisutch. Comp. Biochem. Physiol. 26(2): 381-398.

Ntabo, J.K. (2012). Tolerance, survival rate and growth of tilapia (Oreochromis niloticus) fingerlings at different salinity levels. Rep Ocean Public.

Ried, S.G.; Sundin, L. and Milson, W.K. (2006). The Physiology of Tropical Fishes, Elsevier, Academic Press, Italy.

Ronald, N.; Gladys, B. and Gasper, E. (2014). The effects of stocking density on the growth and survival of Nile Tilapia (Oreochromis niloticus) fry at Son Fish Farm. J Aquac Res Dev., 5(2). 
Sifa, L.; Chenhong, L.; Dey, M.; Gagalac, F. and Dunham, R. (2002). Cold tolerance of three strains of Nile tilapia, Oreochromis niloticus, in China. Aquacult., 213(1-4): 123-129.

Smitherman, R.O.; Khater, A.A.; Cassell, N.I. and Dunham, R.A. (1988). Reproductive performance of three strains of Oreochromis niloticus. Aquacult., 70(1-2): 29-37.

Wang, Y.; Barton, M.; Elliott, L.; Li, X.; Abraham, S.; O'Dea. M. and Munro, J. (2017). Bacteriophage therapy for the control of Vibrio harveyi in greenlip abalone (Haliotis laevigata). Aquacult., 473: 251-258. 